\title{
Continuing Medical Education
}

\section{Hearing Impairment in Old Age}

\author{
Detection, Treatment, and Associated Risks

\begin{abstract}
Jan Löhler, Mario Cebulla, Wafaa Shehata-Dieler, Stefan Volkenstein, Christiane Völter, Leif Erik Walther
\end{abstract}

Department of Ear, Nose and Throat Medicine Universitätsklinikum Schleswig-Holstein,

Campus Lübeck: PD Dr.

med. habil. Jan Löhler

German Center of

Oto-Rhino-Laryngology,

Head and Neck Surgery

(DSZ HNO), Bonn:

PD Dr. med. habil. Jan

Löhler, Prof. Dr. med.

Leif Erik Walther

Otolaryngological practice, Bad Bramstedt:

PD Dr. med. habil.

Jan Löhler

Department of

Oto-Rhino-Laryngology,

Plastic, Aesthetic and

Reconstructive Head

and Neck Surgery,

Division of Pedaudiology,

Phoniatrics and

Electrophysiology,

University Hospital of

Würzburg, $\mathrm{CHC}$,

Würzburg: Prof. Dr.-Ing.

Mario Cebulla

Prof. Dr. med./ET Wafaa

Shehata-Dieler

St. Elisabeth- Hospital,

Clinics of the Ruhr

University of Bochum,

Ear, Nose and Throat

Clinic, Head and Throat

Surgery, Ruhr University

of Bochum: PD Dr. med.

Stefan Volkenstein,

PD Dr. med. Christiane

Völter

Otolaryngological group practice, Sulzbach

(Taunus): Prof. Dr. med. Leif Erik Walther

Department of Otorhinolaryngology, Head and Neck Surgery, Sleep Disorders Center, University Hospital

Mannheimm:

Prof. Dr. med.

Leif Erik Walther

\section{Summary}

Background: Hearing impairment associated with old age (presbycusis) is becoming more common because the population is aging.

Methods: This review is based on publications retrieved by a selective search in Medline and Google Scholar, including individual studies, meta-analyses, guidelines, Cochrane reviews, and other reviews.

Results: The cardinal symptom of presbycusis is impaired communication due to bilateral hearing impairment. Patients may be unaware of the problem for a long time because of its insidious progression. Evidence suggests that untreated hearing impairment in old age can have extensive adverse effects on the patient's mental, physical, and social well-being. Early detection is possible with the aid of simple diagnostic tests or suitable questionnaires. In most cases, bilateral hearing aids are an effective treatment. Surgery is rarely indicated. For patients with uni- or bilateral deafness, a cochlear implant is the treatment of choice. These treatments can improve many patients' quality of life.

Conclusion: The small amount of evidence that is currently available suggests that presbycusis is underdiagnosed and undertreated in Germany. Early detection by physicians of all specialties, followed in each case by a specialized differential diagnostic evaluation, is a desirable goal.

\section{Cite this as:}

Löhler J, Cebulla M, Shehata-Dieler W, Volkenstein S, Völter C, Walther LE: Hearing impairment in old age—detection, treatment, and associated risks. Dtsch Arztebl Int 2019; 116: 301-10. DOI: 10.3238/arztebl.2019.0301

mpaired hearing is widespread. According to World Health Organization criteria, it is one of the most common health deficits in human beings (1), with 450 million people affected worldwide (2). Hearing disorders are most common in old age. Progressive sensorineural hearing loss in old age, usually bilateral, is referred to as presbycusis (3). About one-third of those affected are aged 65 or over. Among over- 60 s, more than $20 \%$ of those surveyed had trouble with their hearing, and among over-70s the figure was more than $30 \%$ (4). Data on the prevalence of impaired hearing and the use of hearing aids in Europe and in Germany are incomplete, partly because of variations in the definition of what constitutes a significant level of hearing loss $(5,6)$. There are no generally accepted figures. One recent study of certain parts of
Germany reports that, in total, $16.2 \%$ of all adults are hearing-impaired and $6.5 \%$ of all adults use hearing aids (7). In total, 20 to 30 million adults in Germany are reported to have a hearing impairment (6). A distinction must be maintained between presbycusis and other diseases leading to hearing loss that can appear at any age including old age; compared to presbycusis, these are responsible for only a small part of all hearing loss in older patients. Age and hearing loss may possibly be indirectly associated in time, but there is no immediate causal connection (8).

At present only about $16 \%$ of all patients with a hearing impairment have been fitted with hearing aids (9). Without treatment, impaired hearing can affect not just the daily life and the quality of life of the

\section{Presbycusis}

Presbycusis is the name given to bilateral progressive sensorineural hearing loss in old age.

\section{Chief symptom}

The chief symptom of presbycusis is a growing impairment of the ability to discriminate speech. 

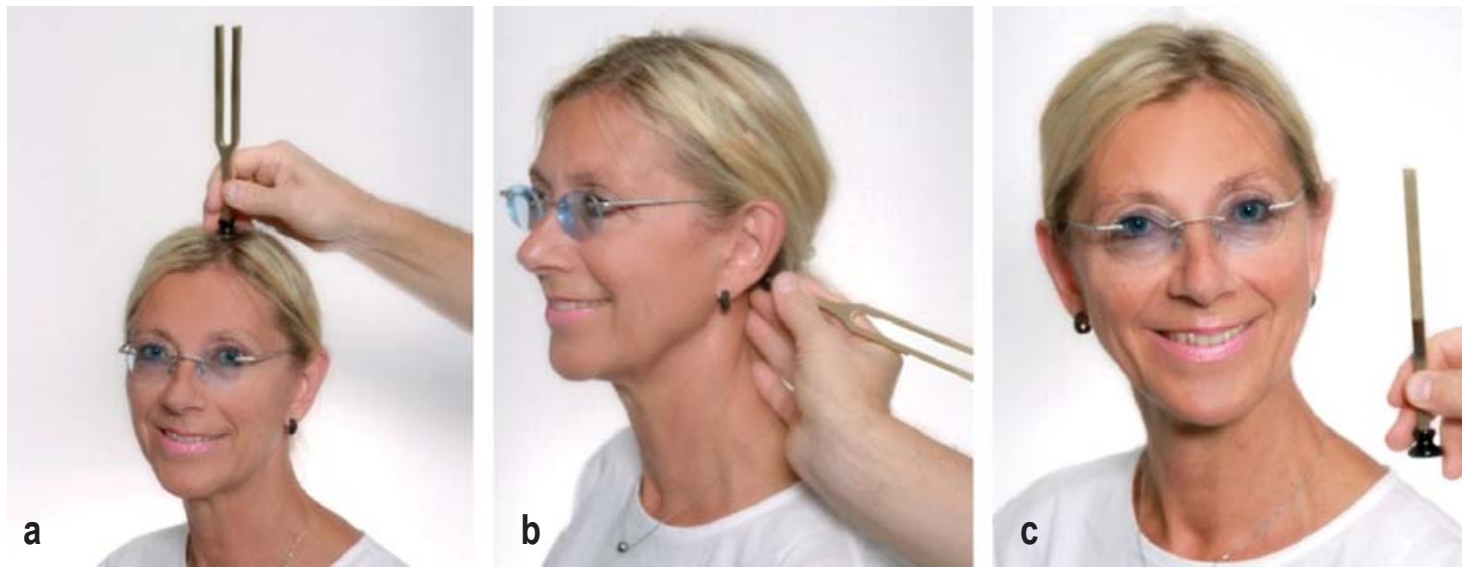

Figure 1: a) Weber test. For this test, the handle of a vibrating $(440 \mathrm{~Hz})$ tuning fork is placed on the top of the patient's head. Patients with normal hearing in both ears will hear the sound equally in both ears. In a patient with right-side hearing loss, if the sound of the tuning fork is heard as louder on the right side, this suggests either a conductive or an outer-ear impairment. If, however, the sound is heard as louder on the left side, this indicates sensorineural hearing impairment on the right side. b) and c) Rinne test. In this test, the vibrating tuning fork is placed first on the mastoid (to test bone conduction) behind the affected ear. The patient is asked to say whether he or she can hear the tone, and the moment at which the sound is no longer heard. The tuning fork is then immediately held just by the outer ear (to test air conduction). If the patient can still hear the tone with the tuning fork in this position, the Rinne test result is positive ("normal finding"). If the tone is not heard, the test result is negative.

person affected, but possibly also the genesis and course of various diseases related to old age. It is for this reason that we believe that non-otolaryngologists should become more aware of the importance of early diagnosis and treatment of presbycusis. To this end, we have carried out a selective literature search on Medline and Google Scholar. The inclusion criteria were "hearing impairment," "presbycusis," "hearing aid fitting," and "surgical treatment"; the exclusion criterion was "age under 50 years."

\section{Learning objectives}

After reading this article, the reader should:

- Have an overview of the clinical features, early signs, and pathophysiology of age-related hearing loss;

- Be familiar with the consequences of age-related hearing loss for the person affected;

- Know the possible options for treatment of presbycusis.

\section{Patient history}

The main symptom of bilateral hearing loss - and not just in old age - is a progressive communication disorder caused by a reduced ability to discriminate speech (3). Frequently, the first symptom is impaired hearing in conversation under difficult acoustic conditions, such as with ongoing background noise, in an echoing room, or where there is a large distance between the speaker and the hearer. Difficulties can also arise in locating the person who is speaking (directional hearing). The communication deficit in presbycusis arises gradually, so individuals can compensate for it to a greater or lesser extent, often for some considerable time $(10,11)$.

When advanced, the hearing impairment affects the person's ability to follow and understand one-to-one conversation in a quiet environment and in situations of daily living (watching television, listening to the radio, speaking on the telephone), with the result that the content of the conversation is only partly understood. The person affected tries to make up the information deficit by asking, or by turning up the volume, or, later, by avoiding such situations altogether (social withdrawal). Information supplied by persons other than the patient him- or herself regarding this can be helpful in the history taking.

The reduced hearing of higher frequencies that predominates in early presbycusis can also mean that the voices of different speakers can no longer be told apart by their individual overtone frequencies. This effect can manifest even in a person with a relatively

\section{Attempts to compensate}

The hearing-impaired patient attempts to compensate for the untreated presbycusis by associative mechanisms and by avoiding difficult hearing situations.

\section{Decompensation}

Quite ordinary disorders of the ear can allow previously masked presbycusis to become manifest. 


\section{Mini Audio Test (MAT) to identify hearing loss in persons aged 50 years or over}

Please answer spontaneously, without thinking too much. If a situation described is not familiar to you, please try to imagine a similar one that is.

Please give an answer to all the questions.

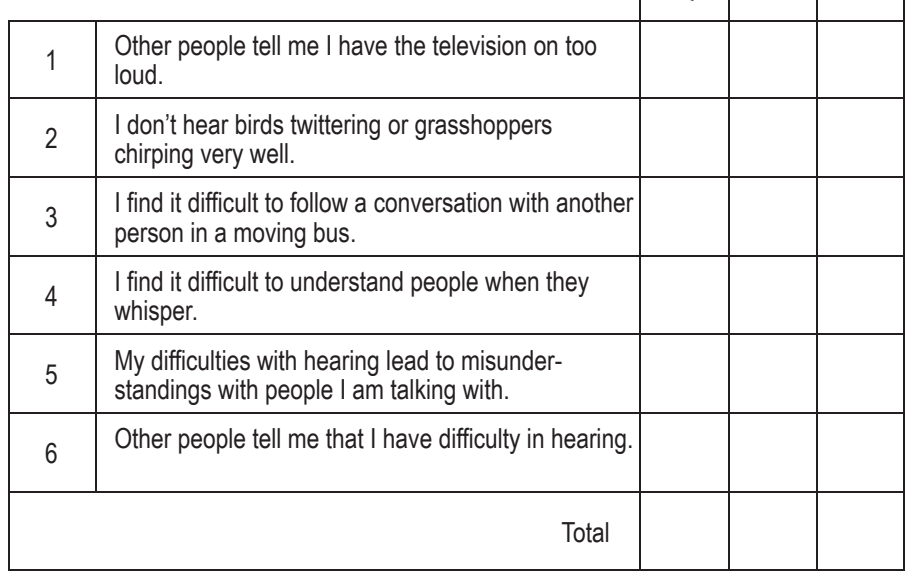

Figure 2: Mini Audio Test for early screening of hearing impairment (16).

Further specialist otolaryngological diagnostic investigation is required in patients aged 50 or over (age group $[A G] 1$ ) with a total score of 2 or more, or patients aged 60 or over (AG 2) with a total score of 3 or more (sensitivity AG1: 0.66. AG2: 0.69; specificity AG1: 0.62, AG2: 0.80 ; positive predictive value $A G 1$ : 0.60, AG2: 0.89; negative predictive value AG1: 0.49, AG2: 0.30).

\section{Answer scores:}

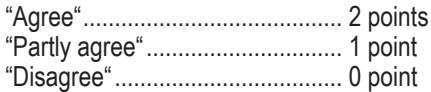

"Disagree"

Add up the total number of points. low-grade, even unilateral, reduction of hearing, as it impairs binaural hearing. As the hearing loss progresses, the ability to distinguish the high-frequency consonants in speech is also lost. At this point, associative mechanisms and guesswork about what might be meant gradually start to replace actual understanding of the speech contents (3).

The restricted understanding of speech may be accompanied by tinnitus, an accelerated rate of loudness growth in the hearing range (recruitment), general sensitivity to sound (hyperacusis), or a nonspecific sensation of pressure or fullness in the ear. Other symptoms, such as vertigo or impaired balance, pain (otalgia), secretion from the ear (otorrhea), a difference between the two ears in the perception of the pitch of a single sound (diplacusis), and fluctuating disorders of hearing usually indicate some other cause than presbycusis or represent a comorbidity (3). Whatever the case, however, loss of hearing is a symptom that should always be referred for differential diagnosis by a specialist. Often it is quite ordinary events, such as blocking of the auditory canal by earwax, or a middle ear effusion associated with an upper airway infection, that lead patients to become aware of their presbycusis as a

\section{Early diagnosis}

Early diagnosis of hearing loss is essential if effective treatment is to be initiated and secondary disorders prevented. pronounced communication disorder that has existed for years, prompting them to seek the help of a physician.

For some time the risk of developing impaired hearing from listening to loud music has been under debate. Although temporary reductions in hearing have been demonstrated (12), a review article showed that most studies have not found a significant association between pure-tone audiometric loss of hearing and exposure to loud music (13). No longitudinal studies have been carried out on this topic.

\section{Early diagnosis of presbycusis}

Early diagnosis of hearing loss is essential if effective treatment is to be initiated and secondary disorders prevented. Whisper tests, finger rub tests, and online hearing tests can provide indications of a loss of hearing, but their performance has not been standardized, which reduces their information value. The classic Weber and Rinne tests using a tuning fork are suitable for basic screening to distinguish between hearing loss due to loss of bone conductivity (middle ear) and sensorineural (inner ear) hearing loss (Figure 1) $(14,15)$. To ensure that poor hearing is identified early, it is worth assessing everyday hearing ability at regular intervals
Inventory of everyday hearing ability

One option in Germany is the Mini Audio Test (MAT) developed for the German-speaking countries, which has been specifically designed for use by non-otolaryngologists and is able to identify at least a proportion of patients with significant hearing loss without the use of any other equipment. 


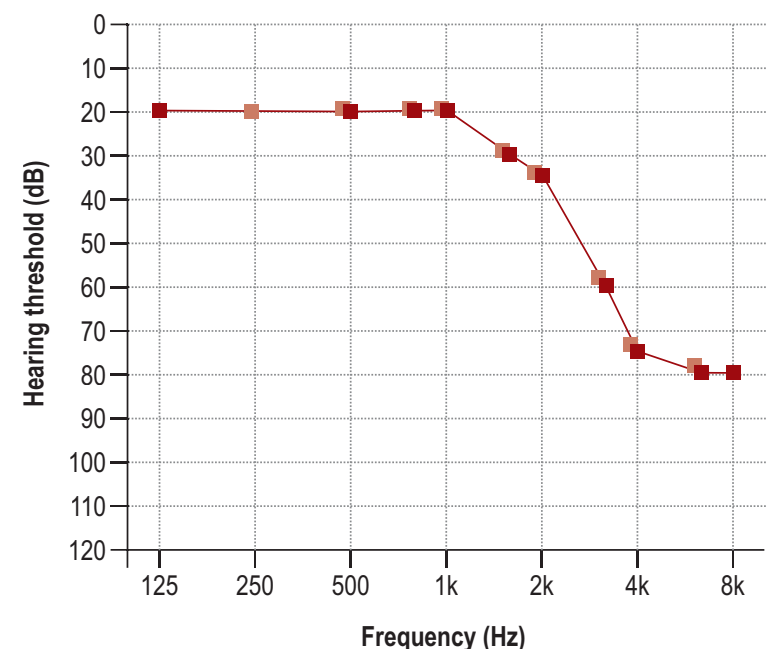

Right ear - dB HL

Bone conduction right ear

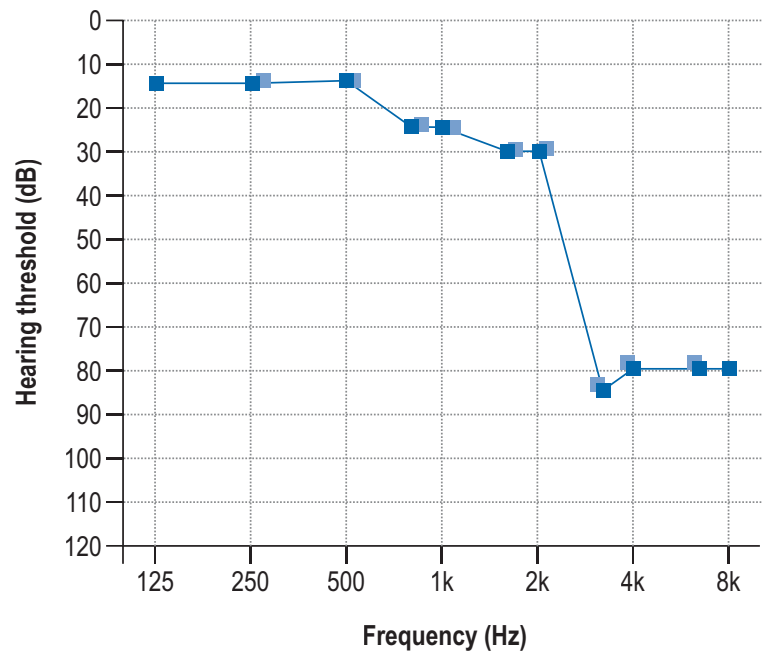

Left ear $-\mathrm{dB} H \mathrm{HL}$

Bone conduction left ear

Typical pure-tone audiogram in presbycusis (bilateral, almost symmetrical, predominantly high-frequency sensorineural hearing impairment)

from the age of 50 onward. One option for this in Germany is the Mini Audio Test (MAT) developed for the German-speaking countries. This test is specifically designed for use by non-otolaryngologists and is able to identify at least a proportion of patients with significant hearing loss without the use of any other equipment (Figure 2) (16). Patients with suspected hearing loss-e.g., an abnormal MAT result-should be promptly referred to an otolaryngologist for further investigation.

Interestingly, people aged between 50 and 60 are more aware of their incipient hearing loss than are those who are over the age of 60 , even though the prevalence of presbycusis is higher in the latter group (16). It may be that over time people become used to their hearing impairment, or perhaps denial is in play. For this reason, a negative screening result does not rule out loss of hearing.

Diagnostic audiology for impaired hearing in old age The clinical investigation of patients with hearing disorders includes inspection of the outer ear. The

\section{Pathophysiological aspects}

With presbycusis, there is a slowly progressive sensorineural loss of hearing from about the age of 50 onwards. It proceeds gradually and without any other obvious cause and is due to morphological and functional changes in the inner ear (cochlea), the auditory nerve, and central auditory cortex. nature and extent of the patient's perceived hearing loss is assessed using pure-tone and speech audiometric procedures supplemented by questionnaires.

Pure-tone audiometry measures the degree of hearing loss (HL) in decibels (dB) at specified frequencies in Hertz $(\mathrm{Hz})$. The main feature of presbycusis is approximately symmetrical bilateral impairment of hearing with a steep reduction in the upper frequencies (Figure 3); this increasing, age-dependent loss of hearing is defined in DIN EN ISO 7029 (17).

Speech audiometry measures speech discrimination with and without the presence of background noise. The test most frequently used in the Germanspeaking countries is the Freiburg monosyllabic test (18-20), which tests patients' absolute recognition of single-syllable words at defined loudness with and without background noise. It is also an important part of testing a patient's hearing improvement after hearing aids have been fitted or after surgical treatment. The patient's subjectively experienced hearing impairment is assessed using the Abbreviated Profile of Hearing Aid Benefit (APHAB) questionnaire

\section{Influencing factors}

In addition to genetic predisposition, physiological processes and factors that are ongoing throughout life play an important part in the pathogenesis of presbycusis. Apart from cochlear deficits, age-related changes in the auditory cortex also play a significant role. 
(21-23), which asks about the patient's ability to hear in various everyday situations. A German version of the APHAB questionnaire is available free of charge (www.quihz.de).

\section{Pathophysiological aspects}

With presbycusis, there is a slowly progressive sensorineural loss of hearing from about the age of 50 onwards. It proceeds gradually and without any other obvious cause and is due to morphological and functional changes in the inner ear (cochlea), the auditory nerve, and the central auditory cortex $(10,11)$. The first to be affected are the higher frequencies of the hearing range, followed later by the middle and lower frequencies. These changes lead to impairment of the hearing function in the form of a raised hearing threshold and decreased frequency resolution (24). Genetic factors have now been identified in age-related hearing impairment but are not relevant to treatment $(25$, 26). A classification exists that was produced by Schuknecht $(27,28)$ in the 1960 s and is based on the results of audiometric studies and histological findings in petrous bones (Table 1). No exact pathomechanisms are known $(3,24,29)$. Animal studies have shown degeneration of the stria vascularis of the cochlear duct. This occurs together with a deficit in $\mathrm{Na}^{+}-\mathrm{K}^{+}$-ATPase in aging animals and affects the endocochlear potential (30). Changes in the outer and middle ear make only a minor contribution to the development of presbycusis (31). Age-related changes in the central auditory nerve system have been suggested as a further neural basis for development of the deficit $(32,33)$. On top of this, there is an age-related deficit in auditory temporal processing that is unrelated to hearing loss (34).

\section{Geriatric aspects and possible associations with secondary disorders \\ Hearing loss, dementia, and cognition}

In recent years, interest in interactions between auditory and sensory performance and cognitive factors has grown considerably (35). Hearing is intimately connected to cognition. Speech discrimination is not dependent on bottom-up sensory processing alone (36), in which acoustic information is relayed from the primary auditory cortex to superordinate regions of the brain. In unfavorable auditory situations, successful speech discrimination is only possible by utilizing explicit processing via the top-down mechanisms, one of which is cognition: in top-down mechanisms, functionally higher brain regions influence areas that are

\section{Cognition}

Hearing and cognition appear to be mutually influential. There are indications that an improvement in hearing can partially improve some cognitive domains.
TABLE 1

\section{Types of presbycusis (based on Schuknecht $[27,28]$ )}

\begin{tabular}{|c|c|}
\hline Type & Description \\
\hline Sensory & $\begin{array}{l}\text { Caused by damage to outer hair cells at the basal turn of the } \\
\text { cochlea (hearing loss in the high frequency range, } 5 \% \text { of cases) }\end{array}$ \\
\hline Neural & $\begin{array}{l}\text { Degeneration of the ganglion cells, shown by a moderate down- } \\
\text { ward slope of the pure-tone threshold towards high frequency } \\
\text { and a sharp drop in speech discrimination compared to the } \\
\text { pure-tone threshold (e55). Based on histological data, the loss of } \\
50 \% \text { or more of } 35500 \text { cochlear neurons is used as the criterion } \\
\text { of neural presbycusis. Otte et al. (e56) showed that about } 2100 \\
\text { neurons are lost in every decade. }\end{array}$ \\
\hline Metabolic & $\begin{array}{l}\text { Caused by atrophy of the stria vascularis (slowly progressive } \\
\text { hearing loss with flattening of the audiogram and good speech } \\
\text { discrimination). The loss of strial tissue results in impaired } \mathrm{K}^{+} \\
\text {recycling, leading in turn to a decrease in endolymphatic } \\
\text { potential (EP) (e57). }\end{array}$ \\
\hline $\begin{array}{l}\text { Cochlear } \\
\text { conductive }\end{array}$ & $\begin{array}{l}\text { This is described (hypothetically) as a degenerative change } \\
\text { resulting from stiffness of the basilar membrane (e55) }\end{array}$ \\
\hline Mixed presbycusis & A combination of the types described above \\
\hline $\begin{array}{l}\text { Indeterminate } \\
\text { presbycusis }\end{array}$ & $\begin{array}{l}\text { In about } 25 \% \text { of cases of hearing loss, no association can be } \\
\text { shown between the audiometric pattern and pathological } \\
\text { changes in the cochlea (e55, e58) }\end{array}$ \\
\hline
\end{tabular}

"upstream" of them. The working memory in particular seems to play a special role in this (37).

Epidemiological studies have shown that people with hearing loss do not just perform worse in the Digit Symbol Substitution Test $(38,39)$. As shown by a longitudinal study, their relative risk of developing dementia over the following decade is also increased: with a low-grade hearing impairment (average hearing loss of a maximum of $40 \mathrm{~dB}$ in the octave frequency range between 0.5 and $4 \mathrm{kHz}$ ) it is 1.8 times as high, and with moderate hearing impairment (max. 70 dB PTA-4) it is three times as high. A greater degree of hearing loss was associated with a five-fold risk of dementia, but this group consisted of only two probands (40). The authors infer that it is not possible to conclude whether the hearing loss is a risk factor for dementia or merely a marker for dementia. The association was confirmed by another study (e1). According to one study, this risk appears not to exist to the same extent in users of hearing aids (e2); on the other hand, Lin et al. found using hearing aids not to be associated with a lower risk of dementia (40).

A recent meta-analysis of 36 studies including a total of 20000 participants also found a statistically

\section{Risk of comorbidities}

Untreated hearing impairment appears to be associated with an increased risk of falls or depression. 

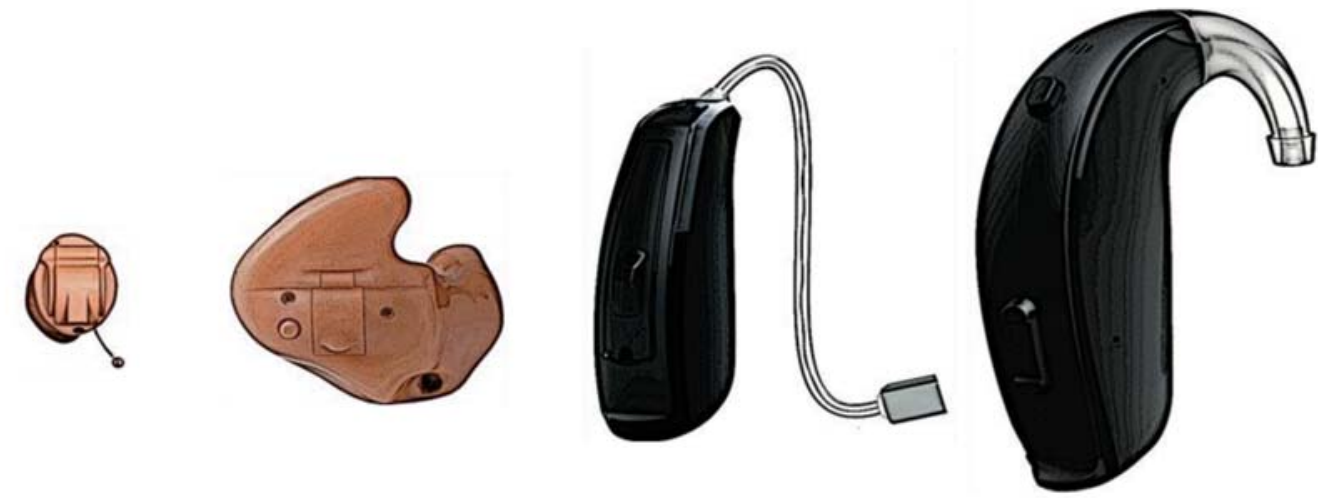

Figure 4: Types of hearing aid design (schematic), from left to right: Completely In Canal (CIC), In The Ear (ITE),

Receiver In Canal (RIC), and Behind The Ear (BTE)

significant, although lower, association between reduced hearing and various areas of cognition (odds ratio [OR]: 1.22 to 2.00), and also between hearing impairment and the occurrence of dementia (OR: 1.28 to 2.42) (e3); however, this was not significant for Alzheimer's disease. This means that impaired hearing could be a risk factor for the occurrence of dementia (e4). A difficulty in this debate is that hearing and cognition are so closely entwined that it can be hard to separate them (e5).

Apart from a common underlying pathophysiologic cause, another alternative could be sensory deprivation resulting in social isolation. This suggestion is supported by EEG studies carried out by Campbell and Sharma in 2013, which showed increased activation of frontal cortical areas in adults with only mild to moderate postlingual hearing loss (e6).

To what extent auditory rehabilitation might be able to contribute to slowing down cognitive decline in old age is currently being investigated (e7, e8); the latter study - although lacking a control group-reports that the adjusted ability to remember 10 words ("episodic memory score") was significantly improved by hearing aids $(\beta: 1.53)$ and the further loss of episodic memory was slowed down ( $\beta$ : -0.02 vs. $-0.1)$. In elderly patients who received a cochlear implant because of high-grade hearing loss, early studies show partial improvement in some cognitive domains even just a few months after the implantation and subsequent auditory rehabilitation (e9, e10). To date, no results of randomized controlled studies have been published (e11-e13).

\section{Hearing loss and risk of falls}

Several longitudinal studies (e14-e16) and a systematic review (e17) have shown impaired hearing to be an independent risk factor for falling in older patients; the causal connection is as yet unclear. Lin and Ferrucci (e18) reported that an increased risk of falls should be expected in older adults with a hearing loss of $>25 \mathrm{~dB}$ (PTA-4), while a hearing impairment of $10 \mathrm{~dB}$ was associated with a 1.4-fold increased risk of falling (adjusted OR: 1.6)

Reduced speech discrimination requires extra cognitive support to compensate for the auditory deficit. It is proposed that this reduces the cognitive capacity available for other physical functions and tasks, including locomotion and balance, and that this could contribute to falls (e19). Other mechanisms, such as a concomitant disorder of the cochlea, the organ of both hearing and balance, with consequent impairment of spatial and directional hearing and acoustic orientation, are being discussed at present (e14, e18). The results of cross-sectional studies show that hearing rehabilitation with hearing aids contributes to improved static and dynamic balance (e20, e21). So far no randomized studies have been carried out.

\section{Hearing loss and depression}

In old age, loss of hearing is associated with an increased risk of developing symptoms of depression or

\section{Hearing aids}

The most common method of hearing rehabilitation in presbycusis is the prescription of hearing aids. Bilateral aids are the norm. Standard hearing aids (i.e., those funded by the statutory health care system without additional payment by the patient) enable most patients to achieve adequate rehabilitation of their hearing loss.

\section{Other advantages of hearing aids}

Hearing aids can probably have a preventive effect against depression and help to improve balance. 
anxiety (OR: 1.63 to 1.85 ), and an increased rate of suicidal ideation (OR: 1.29 to 1.47 ) (e22-e24), especially if visual impairment is also present (e22).

At the neuronal level, activation of the cognitive control network and deafferentation-induced atrophy in certain frontal regions of the brain are believed to be responsible for this. By reducing cognitive reserves, these changes could lead to dysfunction or disruption of normative emotion reactivity and regulation (e25). In one study Han et al. showed that auditory rehabilitation can have a preventive effect against the development of depression (e26).

\section{Hearing loss, risk of hospitalization, and systemic diseases}

Loss of hearing is associated with an increased risk of hospitalization (OR: 1.32, adjusted for demographic factors and cardiovascular risks) (e27). A study in the US $(n=53$ 111) showed that hearing loss above the age of 65 is generally associated with increased disease burden, although the possible causes and potential for reduction of these risks by provision of hearing aids need further investigation (e28, e29). Furthermore, impaired hearing leads to deterioration of communication between the physician and the patient and of the quality of medical care (e30).

\section{Options for treatment of hearing loss in older patients}

Evidence for the treatment of hearing loss is limited, because prospective longitudinal and blinded studies are impossible for both ethical and practical reasons. Rehabilitation with hearing aids may be considered for all sensorineural hearing disorders; bilateral provision of aids is the general rule because of the great importance of directional hearing. One review study showed that in every case hearing rehabilitation improves the quality of life of the patient concerned (e31). This applies even to patients who continue to experience great difficulty even with hearing aids (e32).

\section{Hearing aid rehabilitation}

There are a great many varieties of hearing aid, e.g., inthe-ear (ITE) versus behind-the-ear (BTE). The designs are also very variable and easy to adapt to individual needs (Figure 4). The decision as to whether hearing aids should be prescribed is made on the basis of examination by an otolaryngologist in accordance with the provisions of the German Federal Joint Committee guideline on prosthetic aids (e33). Hearing aid acousticians then choose suitable hearing aids together with

\section{Follow-up of hearing aid users}

Patients who wear hearing aids must receive regular follow-up from otolaryngologists and hearing aid acousticians. This is the only way to ensure that any medical complications, potentially dangerous secondary disorders, or technical problems are identified in good time. the patient and fit them. Finally, the otolaryngologist tests the effectiveness of the aids and records the outcome (e33). With early treatment, very good rehabilitation of the hearing impairment can be achieved in the great majority of cases (e31); this review article quoted three studies in which social and emotional functioning, communication and cognitive abilities, depressive symptoms, and quality of life as a whole were significantly improved by hearing aids, although the latter was not improved to the level of those with normal hearing. A Cochrane review showed that hearing aids had a large beneficial effect (standardized mean difference [SMD]: -26.47) on hearing-specific health-related quality of life, a small beneficial effect (SMD: -0.38) on general health-related quality of life, and a large beneficial effect (SMD: -1.88) on the ability to listen in adults with mild to moderate hearing loss (e34). Standard hearing aids (i.e., those funded by the statutory health care system without additional payment by the patient) enable most patients to achieve good compensation of their hearing loss (e35).

Otolaryngological assessment of the outcome of treatment is structured in accordance with the quality control agreement between the National Association of Statutory Health Insurance Physicians (Kassenärztliche Bundesvereinigung) and the National Association of Statutory Health Insurance Funds (Spitzenverband der Krankenkassen) (e36). Even after they have been successfully fitted with hearing aids, patients with impaired hearing are regularly followed up by otolaryngologists and hearing aid acousticians in order to check that the rehabilitation has been effective and to diagnose any medical or technical problems at an early stage. There is a great need for improvement in this area: one recent study showed that the improvement in hearing required by the guideline, compared to the situation without hearing aids, was not achieved in 56\% of cases (e37). Moreover, regular otolaryngological check-ups can lead to early identification of common comorbidities that are also accompanied by loss of hearing and have been masked by the existence of presbycusis. As for all patients with chronic health conditions, those with presbycusis should be under the care of an otolaryngologist for the rest of their lives (e38).

The reasons most often given by those affected for not using hearing aids are difficulties with the fit of the earpiece and the discomfort caused by loud noises (e39, e40). Auditory rehabilitation therapy can improve patient acceptance of hearing aids and improve central processing (e41). However, another Cochrane

\section{Surgical treatment}

Treatment of presbycusis only very rarely involves surgery. It is an option in, for example, patients with chronic inflammation of the auditory canal or diseases of the middle ear. 
review of 37 studies showed that as yet no results have been published on the long-term, successful, regular use of hearing aids (adherence), which may be partly due to the variable endpoints of the studies analyzed (e42). Future studies should concentrate on long-term results where the key goals of improved hearing and hearing aid use are uniformly defined, as only then is it even possible to measure change during the rehabilitation process.

\section{Surgical treatment to improve hearing}

Depending on the nature of the hearing loss, various surgical procedures may be considered even in older patients. Once again, however, the evidence is limited. Risks associated with surgery of the middle ear include, rarely, impairment of taste, cochlear injury (leading to impaired function of the organs of hearing and balance), and iatrogenic injury to the facial nerve. In patients with chronic inflammation of the auditory canal, or those with allergic reactions to materials contained in conventional hearing aids, bone-anchored hearing systems can be an option for treatment. Within the limits set by the medical and audiological indication criteria and patients' individual anatomy, these patients can be offered the prospect of improved speech recognition and a marked improvement in their quality of life (e31).

In patients with chronic middle ear disease, such as cholesteatoma with its possibility of life-threatening complications, surgical removal of the focus of inflammation is of primary importance; this is usually accompanied by an improvement in hearing (e43). Even older patients with otosclerosis in addition to presbycusis can often be successfully treated by stapedioplasty (e44).

\section{Active middle ear implants}

If, despite the presence of audiological criteria in a patient, conventional hearing aids are appropriately indicated but for some reason cannot be fitted (e.g., due to some anatomical peculiarity or chronic inflammation), or if they have been fitted but have not resulted in satisfactory hearing improvement, various active middle ear implants are available (e45, e46). With these, mechanical stimulation takes place along the ossicular chain or at the round window. While purely conductive hearing impairment can be well treated with hearing systems anchored directly to the skull, middle ear implants have advantages in the treatment of sensorineural or mixed forms of hearing loss. For this small group of selected patients, these systems can be a further option for treatment to maintain verbal communication with the outside world.

\section{Cochlear implants}

In patients who are completely deaf, or those with inadequate cochlear function, the auditory nerve can be directly stimulated electrically by a cochlear implant (CI). Even older patients derive great benefit from a CI in terms of speech recognition and quality of life, and this can counteract social isolation or cognitive deficit (e10, e47-e51). There is no age limit for placement of a $\mathrm{CI}$ - the perioperative risk is no greater in older patients than in younger ones (e52). Using electrodes specially adjusted to the hearing loss pattern in the individual case, either the entire frequency range or just the upper range can be stimulated electrically. Patients with unilateral postlingual hearing loss can also benefit from a CI despite having normal hearing in the other ear, because of its effect on directional hearing and the ability to hear in a noisy environment (e13, e53, e54).

\section{Conflict of interest statement}

Dr. Volkenstein has had conference fees and travel and accommodation expenses reimbursed by MEDEI and Straubing.

The other authors declare that no conflict of interest exists.

Manuscript received on 17 December 2018, revised version accepted on 21 March 2019

Translated from the original German by Kersti Wagstaff, MA.

\section{References}

1. Mathers $C$, Smith $A$, Concha M: Global burden of hearing loss in the year 2000. www.who.int/healthinfo/statistics/bod_hearingloss.pdf (last accessed on 27 March 2019)

2. WHO: Deafness and hearing loss: www.who.int/news-room/fact-sheets/ detail/deafness-and-hearing-loss (last accessed on 27 March 2019).

3. Mazurek B, Stöver T, Haupt H, Gross J, Szczepek A: Die Entstehung und Behandlung der Presbyakusis. HNO 2008; 56: 429-35.

4. Streppel M, Walger M, von Wedel H, Gaber E: Gesundheitsberichtserstattung des Bundes. Hörstörungen und Tinnitus. www.edoc.rki.de/bitstream/ handle/176904/3181/ 20Vo4CXYDBpeQ_41.pdf?sequence=1\&isAllowed=y (last accessed on 27 March 2019).

5. Roth TN, Hanebuth D, Probst R: Prevalence of age-related hearing loss in Europe: a review. Eur Arch Otorhinolaryngol 2011; 268: 1101-07.

6. Löhler J, Walther LE, Hansen F, et al.: The prevalence of hearing loss among adults in Germany - a systematic review. Eur Arch Otorhinolaryngol 2019; 276: 945-56.

7. von Gablenz P, Hoffmann E, Holube I: Prävalenz von Schwerhörigkeit in Nord- und Süddeutschland. HNO 2017; 65: 663-70.

8. Laubert A, Lehnhardt E: Hörstörungen im Alter. In: Platt D, Haid T, (eds.) Handbuch der Gerontologie - Hals-Nasen-Ohren-Heilkunde. Stuttgart, Jena, New York: G. Fischer 1993; 130-66.

9. Sohn W, Jörgenshaus W: Schwerhörigkeit in Deutschland: Repräsentative Hörscreening-Untersuchung bei 2000 Probanden in 11 Allgemeinpraxen. Z Allg Med 2001; 77: 143-7.

10. Hesse G, Laubert A: Hörminderung im Alter - Ausprägung und Lokalisation. Dtsch Arztebl 2005; 102: A2864-8.

\section{Active middle ear implants}

are a treatment option in selected patients. With these implants, mechanical stimulation takes place along the ossicular chain or at the round window.

\section{Cochlear implants}

A cochlear implant supplies electrical stimulation directly to the auditory nerve. Cochlear implants can be used to treat severe hearing impairment or deafness even in older patients in whom hearing aids have been unsuccessful. 
11. Zahnert T: The differential diagnosis of hearing loss. Dtsch Arztebl Int 2011; 108: 433-44.

12. Gopal KV, Mills LE, Phillips BS, Nandy R: Risk assessment of recreational noise-induced hearing loss from exposure through a personal audio system-iPod touch. J Am Acad Audiol 2018; [Epub ahead of print].

13. le Clercq CMP, van Ingen G, Ruytjens L, van der Schroeff MP: Music-induced hearing loss in children, adolescents, and young adults: a systematic review and meta-analysis. Otol Neurotol 2016; 37: 1208-16.

14. Wahid NW, Attia M: Weber Test. StatPearls. Treasure Island (FL): StatPearls Publishing 2018; PMID: 30252391.

15. Kong EL, Fowler JB: Rinne Test. StatPearls, Treasure Island (FL): StatPearls Publishing 2018; PMID: 28613725.

16. Löhler J, Lehmann M, Segler V, et al.: Der Mini-Audio-Test (MAT) - Eine Screeningmethode auf Schwerhörigkeit für Haus- und Fachärzte. Laryngo Rhino Otol 2019; 98 : 27-34.

17. DIN EN ISO 7029: Akustik - Statistische Verteilung von Hörschwellen in Bezug auf das Alter und das Geschlecht (ISO 7029); Deutsche Fassung, Berlin: Beuth Verlag 2017.

18. Hahlbrock KH: Über Sprachaudiometrie und neue Wörterteste. Arch Ohren Nasen Kehlkopfheilkd 1953; 162: 394-431.

19. Löhler J, Akcicek B, Wollenberg B, et al.: Results in using the Freiburger monosyllabic speech test in noise without and with hearing aids. Eur Arch Oto Rhino Laryngol 2015 272: $2135-42$.

20. Memmeler T, Schönweiler R, Wollenberg B, Löhler J: Die adaptive Messung des Freiburger Einsilbertests im Störschall - Entwicklung einer Messmethode und Vergleich der Ergebnisse mit dem Oldenburger Satztest. HNO 2019; 67: 118-25

21. Cox RM, Alexander GC: The abbreviated profile of hearing aid benefit. Ear Hear 1995 16: $176-86$.

22. Johnson JA, Cox RM, Alexander GC: Development of APHAB norms for WDRC hearing aids and comparisons with original norms. Ear Hear 2010; 31: 47-55.

23. Löhler J: Eigenschaften und klinische Anwendungen des APHAB-Fragebogens als Hilfsmittel in der audiologischen Diagnostik. Habilitationsschrift. Lübeck, 2018.

24. Yamasoba T, Lin R, Someya Sh, Kashio A, Sakamoto T, Kondo K: Current concepts in age-related hearing loss: epidemiology and mechanistic pathways. Hear Res 2013; 303: 30-8.

25. Uchida Y, Sugiura S, Sone M, Ueda H, Nakashima T: Progress and prospects in human genetic research into age-related hearing impairment. Biomed Res Int 2014; 2014: 390601 .

26. Momi SK, Wolber LE, Fabiane SM, MacGregor AJ, Williams FM: Genetic and environmental factors in age-related hearing impairment. Twin Res Hum Genet 2015; 18 : 383-92.

27. Schuknecht HF: Further observations on the pathology of presbycusis. Arch Otolaryngol 1964; 80: 369-82
28. Schuknecht HF, Gacek MR: Cochlear pathology in presbycusis. Ann Otol Rhino Laryngol 1993; 102: 1-16.

29. Ruan Q, Ma C, Zahng R, Yu Z: Current status of auditory ageing and anti-aging research. Geriatr Gerontol Int 2014; 14: 40-53.

30. Schmiedt RA, Lang H, Okamura HO, Schulte BA: Effects of furosemide applied chronically to the round window: a model of metabolic presbyacusis. J Neurosci 2002; 22: 9643-50.

31. Howarth A, Shone GR: Aging and the auditory system. Postgrad Med J 2006; 82 : 166-171.

32. Helfert RH, Sommer TJ, Meeks J, Hofstetter P, Hughes LF: Age-related synaptic changes in the central nucleus of the inferior colliculus of Fischer-344 rats. J Comp Neurol 1999; 406: 285-98.

33. Mazelova J, Popelar J, Syka J: Auditory function in presbyacusis peripheral vs. central changes. Exp Gerontol 2003; 38: 87-94

34. Fitzgibbons PJ, Gordon-Salant S: Auditory temporal processing in elderly listeners. J Am Acad Audiol 1996; 7: 183-9.

35. Jayakody DMP, Friedland PL, Martins RN, Sohrabi HR: Impact of aging on the auditory system and related cognitive functions: a narrative review. Front Neurosci 2018; 12: 125.

36. Rönnberg J, Lunner T, Zekveld A, et al.: The Ease of Language Understanding (ELU) model: theoretical, empirical, and clinical advances. Front Syst Neurosci 2013; 7: 31.

37. Stenfelt S, Rönnberg J: The signal-cognition interface: interactions between degraded auditory signals and cognitive processes. Scand J Psychol 2009; 50: 385-93.

38. Lin FR: Hearing loss and cognition among older adults in the United States. J Gerontol A Biol Sci Med Sci 2011; 66: 1131-36.

39. Lin FR, Ferrucci L, Metter EJ, An Y, Zonderman AB, Resnick SM: Hearing loss and cognition in the Baltimore longitudinal study of aging. Neuropsychology 2011; 25: 763-70.

40. Lin FR, Metter EJ, O'Brien RJ, et al.: Hearing loss and incident dementia. Arch Neurol 2011; 68: 214-20.

\section{Corresponding author:}

Dr. Jan Löhler

Maienbeeck 1

24576 Bad Bramstedt, Germany

loehler@hno-aerzte.de

\section{Cite this as:}

Löhler J, Cebulla M, Shehata-Dieler W, Volkenstein S, Völter C, Walther LE:

Hearing impairment in old age-detection, treatment, and associated risks.

Dtsch Arztebl Int 2019; 116: 301-10. DOI: 10.3238/arztebl.2019.0301

Supplementary material

For eReferences please refer to:

www.aerzteblatt-international.de/ref1719

\section{Further information on CME}

- Participation in the CME certification program is possible only over the Internet: cme.aerzteblatt.de. This unit can be accessed until 21 July 2019. Submissions by letter, e-mail or fax cannot be considered.

- The following CME units can still be accessed for credit:

- "Otitis Externa: Investigation and Evidence-Based Treatment" (issue13/2019) until 23 June 2019

- "Acute Renal Failure of Nosocomial Origin" (issue 9/2019) until 26 May 2019

- "Determinants of Perioperative Outcome in Frail Older Patients" (issue 5/2019) until 28 April 2019

- This article has been certified by the North Rhine Academy for Continuing Medical Education. Participants in the CME program can manage their CME points with their 15-digit "uniform CME number" (einheitliche Fortbildungsnummer, EFN), which is found on the CME card (8027XXXXXXXXXXX). The EFN must be stated during registration on www.aerzteblatt.de ("Mein DÄ") or else entered in "Meine Daten," and the participant must agree to communication of the results. 


\section{CME credit for this unit can be obtained via cme.aerzteblatt.de until 21 July 2019.} Only one answer is possible per question. Please select the answer that is most appropriate.

\section{Question 1}

What is meant by the term "presbycusis"?
a) An isolated impairment of sound conduction in the outer and middle ear
b) Progressive sensorineural hearing loss in old age, usually bilateral, without any other identifiable cause
c) Damage to the outer hair cells
d) An isolated dysfunction of the central nervous system
e) A reversible loss of strial tissue

\section{Question 2}

What is another reason for impaired speech discrimination in age-related hearing loss compared to the pure-tone audiogram?

a) Neural damage and changes in the central auditory nervous system

b) Sensorineural hearing impairment with degenerative changes resulting from stiffness of the basilar membrane

c) Damaged outer hair cells at the basal turn of the cochlea

d) Degeneration of the stria vascularis associated with a loss of $\mathrm{Na}^{+}-\mathrm{K}^{+}$-ATPase

e) Collapse of the cartilaginous outer ear canal

\section{Question 3}

How many adults in Germany probably suffer from significant hearing loss?
a) 0-10 million
b) 10-20 million
c) 20-30 million
d) 30-40 million
e) 40-50 million

Question 4

Which test contributes to a diagnosis of hearing loss?
a) Mini Mental Status Test
b) Mini Audio Test
c) Schilling Test
d) DEMAT 2 Test
e) HSP Test

Question 5

In presbycusis, which frequencies are affected first?
a) The middle frequencies
b) The middle and low frequencies
c) The higher frequencies
d) The low frequencies
e) The high and low frequencies

\section{Question 6}

What can be an indication of chronic hearing impairment in old age?
a) Fluctuating hearing difficulties
b) Increased difficulty in finding words
c) Occurrence of benign postural vertigo
d) Sudden onset of disturbed sleep
e) Reduced ability to discriminate speech, especially in noisy environments

\section{Question 7}

Why is it important to wear hearing aids regularly, all day long if possible?

a) Because it reduces the occurrence of eczema

b) Because it has a cognitive training effect

c) Because you get more out of the hearing aid battery this way

d) Because the hearing aids will be more quickly accepted by family, friends, work colleagues, etc.

e) Because by wearing them all the time one acquires a routine in dealing with them

\section{Question 8}

From whom does a patient with a hearing loss requiring hearing aids obtain the aids?

a) The patient receives a prescription for hearing aids from the otolaryngologist and can use it to buy any hearing aids.

b) The otolaryngologist prescribes a particular hearing aid and the patient obtains it from the hearing aid acoustician.

c) A hearing aid manufacturer receives the prescription from the otolaryngologist and supplies a suitable hearing aid.

d) The hearing aid acoustician chooses a hearing aid together with the patient, based on the prescription from the otolaryngologist.

e) An application for hearing aids is sent to the statutory health insurance company and the aids are then issued by the otolaryngologist.

\section{Question 9}

Which of the following is/are appropriate for distinguishing broadly between middle ear-related conductive hearing loss and cochlear sensorineural hearing loss?
a) Otoacoustic emissions
b) The classical Weber and Rinne tests using a tuning fork
c) Tympanometry
d) Acoustic reflex testing
e) Brainstem audiometry

Question 10

When is surgical treatment indicated for a hearing impairment?
a) In an old patient who refuses to wear hearing aids
b) In a patient with severe chronic inflammatory middle ear infection
c) In a patient with acute otitis externa
d) In a patient in whom degeneration of the ganglion cells has occurred
e) In a patient with marked hyperacusis 
Supplementary material to:

\section{Hearing Impairment in Old Age}

Detection, Treatment, and Associated Risks

by Jan Löhler, Mario Cebulla, Wafaa Shehata-Dieler, Stefan Volkenstein, Christiane Völter, and Leif Erik Walther

Dtsch Arztebl Int 2019; 116: 301-10. DOI: 10.3238/arztebl.2019.0301

\section{eReferences}

e1. Thomson RS, Auduong P, Miller AT, Gurgel RK: Hearing loss as a risk factor for dementia: a systematic review. Laryngoscope Investig Otolaryngol 2017; 2: 69-79.

e2. Amieva H, Ouvrard C, Meillon C, Rullier L, Dartigues JF: Death, depression, disability and dementia associated with self-reported hearing problems: a 25-year study. J Gerontol A Biol Sci Med Sci 2018; 73: 1383-9.

e3. Loughrey DG, Kelly ME, Kelley GA, Brennan S, Lawlor BA: Association of age-related hearing loss with cognitive function, cognitive impairment, and dementia: a systematic review and meta-analysis. JAMA Otolaryngol Head Neck Surg 2018; 144: 115-26.

e4. Livingstone G, Sommerlad A, Orgeta V, et al.: Dementia prevention, intervention, and care. Lancet 2017; 390: 2673-734.

e5. Wayne RV, Johnsrude IS: A review of causal mechanisms underlying the link between age-related hearing loss and cognitive decline. Ageing Res Rev 2015; 23 (Pt B):154-66.

e6. Campbell J, Sharma A: Compensatory changes in cortical resource allocation in adults with hearing loss. Front Syst Neurosci 2013; 7: 71

e7. Castiglione A, Benatti A, Velardita C, et al.: Aging, cognitive decline and hearing loss: effects of auditory rehabilitation and training with hearing aids and cochlear implants on cognitive function and depression among older adults. Audiol Neurootol 2016; 21 (Suppl 1): 21-8.

e8. Maharani A, Dawse P, Nazroo J, Tampubolon G, Pendleton N: Longitudinal relationship between hearing aid use and cognitive function in older Americans. J Am Geriatr Soc 2018; 66: 1130-6.

e9. Mosnier I, Bebear JP, Marx M, et al.: Improvement of cognitive function after cochlear implantation in elderly patients. JAMA Otolaryngol Head Neck Surg 2015; 141: 442-50.

e10. Völter C Götze L, Dazert S, Falkenstein M, Thomas JP: Can cochlear implantation improve neurocognition in the aging population? Clin Interv Aging 2018; 13, 701-12.

e11. Deal JA, Albert MS, Arnold M, et al.: A randomized feasibility pilot trail of hearing treatment for reducing cognitive decline: results from the aging and cognitive health evaluation in elders pilot study. Alzheimers Dement 2017; 3: 410-5.

e12. Nkyekyer J, Meyer D, Blamey PJ, Pipingas A, Bhar S: Investigating the impact of hearing aid use and auditory training on cognition, depressive symptoms, and social interaction in adults with hearing loss: protocol for a crossover trial. JMIR Res Protoc 2018: 7: e85.

e13. Claes AJ, Van de Heyning P, Gilles A, Van Rompaey V, Mertens G: Cognitive performance of severely hearing-impaired older adults before and after cochlear implantation: preliminary results of a prospective, longitudinal cohort study using the RBANS-H. Oto Neurotol 2018; 39: e765-e73,

e14. Viljanen A, Kaprio J, Pyykkö I, et al.: Hearing as a predictor of falls and postural balance in older female twins. J Gerontol A Biol Sci Med Sci 2009; 64: 312-7.

e15. Lin FR, Thorpe R, Gordon-Salant S, Ferrucci L: Hearing loss prevalence and risk factors among older adults in the United States. J Gerontol A Biol Sci Med Sci 2011; 66: 582-90.

e16. Kamil RJ, Betz J, Powers BB, et al.: ABC study. Association of hearing impairment with incident frailty and falls in older adults. J Aging Health 2016; 28: 644-60.

e17. Jiam NT, Li C, Agrawal Y: Hearing loss and falls: A systematic review and meta-analysis. Laryngoscope 2016; 126: 2587-96.

e18. Lin FR, Ferrucci L: Hearing loss and falls among older adults in the United States. Arch Intern Med 2012; 172: 369-71.

e19. Cardin V: Effects of aging and adult-onset hearing loss on cortical auditory regions. Front Neurosci 2016; 10: 199

e20. Rumalla K, Karim AM, Hullar TE: The effect of hearing aids on postural stability. Laryngoscope 2015; 125: 720-3. e21. Weaver TS, Shayman CS, Hullar TE: The effect of hearing aids and cochlear implants on balance during gait. Otol Neurotol 2017; 38: 1327-32.

e22. Simning A, Fox ML, Barnett SL, Sorensen S, Conwell Y: Depressive and anxiety symptoms in older adults with auditory, vision, and dual sensory impairment. J Aging Health 2018 : 898264318781123. [Epub ahead of print].

e23. Cosh S, Carrière I, Daien V, Tzourio C, Delcourt C, Helmer C: Sensory loss and suicide ideation in older adults: findings from the Three-City cohort study. Int Psychogeriatr 2019; 31 : 139-145.

e24. Brewster KK, Ciarleglio A, Brown PJ, et al.: Age-related hearing loss and its association with depression in later life. Am J Geriatr Psychiatry 2018; 26: 788-96.

e25. Rutherford BR, Brewster K, Golub JS, Kim AH, Roose SP Sensation and psychiatry: linking age-related hearing loss to late-life depression and cognitive decline. Am J Psychiatry 2018; 175: 215-24.

e26. Han JH, Lee HJ, Jung J, Park EC: Effects of self-reported hearing or vision impairment on depressive symptoms: a population-based longitudinal study. Epidemiol Psychiatr Sci 2018: 1-13.

e27. Genther DJ, Frick KD, Chen D, Betz J, Lin FR: Association of hearing loss with hospitalization and burden of disease in older adults. JAMA 2013; 309: 2322-4.

e28. McKee MM, Stransky ML, Reichard A: Hearing loss and associated medical conditions among individuals 65 years and older. Disabil Health J 2018; 11: 122-5.

e29. Deal JA, Reed NS, Kravetz AD, et al.: Incident hearing loss and comorbidity a longitudinal administrative claims study. JAMA Otolaryngol Head Neck Surg 2018. [Epub ahead of print].

e30. Mick P, Foley DM, Lin FR: Hearing loss is associated with poorer ratings of patient-physician communication and healthcare quality. J Am Geriatr Soc 2014; 62: 2207-9.

e31. Brodie A, Smith B, Ray: The impact of rehabilitation on quality of life after hearing loss: a systematic review. Eur Arch Otorhinolaryngol 2018; 275: 2435-40.

e32. Lotfi Y, Mehrkian S, Moossavi A, Faghih-Zadeh S: Quality of life improvement in hearing-impaired elderly people after wearing a hearing aid. Arch Iran Med 2009; 12: 365-70.

e33. Gemeinsamer Bundesausschuss: Hilfsmittel-Richtlinie 2017 www.g-ba.de/downloads/62-492-1352/HilfsM-RL 2016-1124 iK-2017-02-17.pdf (last accessed on 28 March 2019).

e34. Ferguson MA, Kitterick PT, Chong LY, Edmondson Jones M, Barker F, Hoare DJ: Hearing aids for mild to moderate hearing loss in adults. Cochrane Database Syst Rev 2017; 9 : CD012023.

e35. AOK: Versorgung der Versicherten ab Vollendung des 18 Lebensjahres mit Hörsystemen. www.aok-gesundheitspartner.de/ by/hilfsmittel/vertraege preise/hoerhilfen/index.html (last accessed on 28 March 2019).

e36. KBV: Vereinbarung von Qualitätssicherungsmaßnahmen nach § 135 Abs. 2 SGB V zur Hörgeräteversorgung. www.kbv.de/media/ sp/Hoergeraeteversorgung.pdf (last accessed on 28 March 2019).

e37. Kronlachner M, Baumann U, Stöver T, Weißgerber T: Untersuchung der Qualität der Hörgeräteversorgung bei Senioren unter Berücksichtigung kognitiver Einflussfaktoren. Laryngorhinootologie 2018; 97: 852-9.

e38. Löhler J, Akcicek B, Wienke A, Hoppe U: Komplikationen bei der Hörgeräteversorgung ohne HNO-Arzt. HNO 2014; 62: 360-6.

e39. McCormack $A$, Fortnum $\mathrm{H}$ : Why do people fitted with hearing aids not wear them? Int J Audiol 2013; 52: 360-8.

e40. Carrasco-Alarcón P, Morales C, Chicuy Bahamóndez M, Alarcón Cárcamo D, Cayul Schacht Á: Elderly who refuse to use hearing aids: an analysis of the causes. CoDAS 2018; 30: e20170198. 
e41. Hesse G, Eichhorn S, Laubert A: Hörfähigkeit und Schwerhörigkeit alter Menschen. HNO 2014; 62: 630-9.

e42. Barker F, Mackenzie E, Elliott L, Jones S, de Lusignan S: Interventions to improve hearing aid use in adult auditory rehabilitation. Cochrane Database Syst Rev 2016; 8: CD010342.

e43. Minovi A, Venjacob J, Volkenstein S, Dornhoffer J, Dazert S: Functional results after cholesteatoma surgery in an adult population using the retrograde mastoidectomy technique. Eur Arch Otorhinolaryngol 2014; 271: 495-501.

e44. Kulakova LA, Poliakova EP, Bodrova IV, Lopatin AS: The results of the surgical treatment of otosclerosis in the elderly subjects]. Vestn Otorinolaringol 2014; (3): 17-9.

e45. Volkenstein S, Thomas JP, Dazert S: Bone conduction and active middle ear implants. Laryngorhinootologie 2016; 95: 352-63.

e46. Leitlinie Implantiere Hörgeräte. 2017; www.awmf.org/uploads/ tx_szleitlinien/017-073I_Implantierbare-Hoergeraete_2018-06.pdf (last accessed on 28 March 2019).

e47. Leitlinie Cochlea-Implantat Versorgung und zentral-auditorische Implantate. 2012; www.awmf.org/uploads/tx_szleitlinien/017-071| S2k Cochlea Implant Versorgung 2012-05-abgelaufen.pdf (last accessed on 28 March 2019).

e48. Jayakody DMP, Friedland PL, Nel E, Martins RN, Atlas MD, Sohrabi HR: Impact of cochlear implantation on cognitive functions of older adults: pilot test results. Otol Neurotol 2017; 38: e289-e95.

e49. Ketterer MC, Knopke S, Häußler SM, et al.: Asymmetric hearing loss and the benefit of cochlear implantation regarding speech perception, tinnitus burden and psychological comorbidities: a prospective follow-up study. Eur Arch Otorhinolaryngol 2018; 275: 2683-93. e50. Knopke S, Olze H: Hörrehabilitation mithilfe von Cochleaimplantaten und kognitive Fähigkeiten. HNO 2018; 66: 364-8.

e51. Garcia-Iza L, Martinez Z, Ugarte A, Fernandez M, Altuna X: Cochlea implantation in the elderly: outcomes, long-term evolution, and predictive factors. Eur Arch Otorhinolaryngol 2018; 275: 913-22.

e52. Büchsenschütz K, Arnolds J, Bagus H, et al.: Operatives Risikoprofil und Hör-Spracherfolg bei älteren Cochlea-Implantat-Patienten. Laryngo Rhino Otol 2015; 94: 670-5.

e53. Junior FC, Pinna M, Alves R, Malerbi A, Bento R: Cochlear implantation and single-sided deafness: a systematic review of the Literature. Int Arch Otorhinolaryngol 2016; 20: 69-75.

e54. Yawn RJ, O'Connell BP, Dwyer RT, et al.: Bilateral cochlear implantation versus bimodal hearing in patients with functional residual hearing: a within-subjects comparison of audiologic performance and quality of life. Otol Neurotol 2018; 39: 422-7.

e55. Merchant SN, Nadol JB, Jr.: In Schuknecht's pathology of the ear $3^{\text {rd }}$ edition. Shelton, CT: People's Medical Pub. House-USA; 2010.

e56. Otte J, Schuknecht HF, Kerr AG: Ganglion cell populations in norma and pathological human cochleae. Implications for cochlear implantation. Laryngoscope 1978; 88: 1231-46.

e57. Pauler M, Schuknecht HF, White JA: Atrophy of the stria vascularis as a cause of sensorineural hearing loss. Laryngoscope 1988; 98 : 754-9.

e58. Nelson EG, Hinojosa R: Presbycusis: a human temporal bone study of individuals with downward sloping audiometric patterns of hearing loss and review of the literature. Laryngoscope 2006; 116 (9 Pt 3 Suppl 112): 1-12. 